\title{
Is there a place for nutritional supplements in the treatment of idiopathic male infertility?
}

\author{
Davide Arcaniolo ${ }^{1}$, Vincenzo Favilla ${ }^{2}$, Daniele Tiscione ${ }^{3}$, Francesca Pisano ${ }^{4}$, \\ Giorgio Bozzini ${ }^{5}$, Massimiliano Creta ${ }^{1}$, Giorgio Gentile ${ }^{6}$, Filippo Menchini Fabris ${ }^{7}$, \\ Nicola Pavan ${ }^{8}$, Italo Antonio Veneziano ${ }^{9}$, Tommaso Cai ${ }^{4}$ on behalf of Young Commision \\ of Italian Andrological Society (SIA) \\ ${ }^{1}$ Department of Urology, University of Federico II, Naples, Italy; \\ ${ }^{2}$ Department of Urology, University of Catania, Catania, Italy; \\ ${ }^{3}$ Department of Urology, Santa Chiara Hospital, Trento, Italy; \\ ${ }^{4}$ Department of Urology, University of Turin, Turin, Italy; \\ ${ }^{5}$ Department of Urology, Istituto Di Ricovero e Cura a Carattere Scientifico, Policlinico San Donato, University of Milan, Milan, Italy; \\ ${ }^{6}$ Department of Urology, Azienda Ospedaliero-Universitaria Policlinico S.Orsola-Malpighi, Bologna; \\ ${ }^{7}$ Department of Urology, University of Pisa, Pisa, Italy; \\ ${ }^{8}$ Department of Urology, University of Trieste, Trieste, Italy; \\ ${ }^{9}$ Department of Urology, Ospedale Madonna delle Grazie, Matera, Italy.
}

\begin{abstract}
Summary Objective: Infertility affects $15 \%$ of couples in fertile age. Male factor is a cause of infertility in almost half of cases, mainly due to oligoasthenoteratozoospermia (OAT). The purpose of this study is to review the effects of nutritional supplements as medical treatment for idiopathic male infertility.

Material and methods: A Pub Med and Medline review of the published studies utilizing nutritional supplements for the treatment of male infertility has been performed.

Results: Clinical trials on Vitamin E, Vitamin A, Vitamin C. Arginine, Carnitine, N-Acetyl-Carnitine, Glutathione, Coenzyme 210, Selenium and Zinc were reviewed. Although there is a wide variability in selected population, dose regimen and final outcomes, nutritional supplements both alone and in combination seems to be able to improve semen parameters (sperm count, sperm motility and morphology) and pregnancy rate in infertile men.

Conclusions: There are rising evidences from published randomized trials and systematic review suggesting that nutritional supplementation may improve semen parameters and the likelihood of pregnancy in men affected by OAT. This improvement, however, is not consistent and there is a wide variation in the treatment regimens used. Well designed and adequately powered RCTs are needed to better clarify the role of nutritional supplements as treatment for male infertility.
\end{abstract}

KEY WORDS: Phytotherapy; Male fertility; Oligoasthenoteratozoospermia; N-Acetyl-Carnitine; Vitamin E;

Semen parameters.

Submitted 15 July 2014; Accepted 31 July 2014

No conflict of interest declared.

\section{INTRODUCTION}

Almost 15\% of all couples trying to conceive are affected by infertility and seek treatment for this condition (1). In a $50 \%$ of childless couples, it is possible to recognize a male-infertility-associated factor (2). Male infertility could be consequence of some definable conditions (varicocele, cryptorchidism, hypogonadism, genetic abnormalities), but in 30-40\% of infertile male no cause may be determined. Such idiopathic infertility is characterized by a decreased number of spermatozoa, decreased sperm motility and abnormal sperm morphology in men with no history of diseases impairing fertility and with normal findings on physical examination and laboratory testing (3). Idiopathic oligoasthenoteratozoospermia is supposed to be determined by several causes, including endocrine disorders, genetic abnormalities or reactive oxygen species (4).

High ROS level and oxidative stress have been implicated in the pathophysiology of male infertility (5) and correlated with sperm DNA damage, reduced sperm motility, impaired fertilization and embryo development (6, 7). ROS affect sperm function as they damage lipids, amino acids, carbohydrates, protein, and DNA of the spermatozoa (8). In human ejaculate there are some endogenous antioxidants, but many studies have shown that seminal antioxidant capacity is suppressed in infertile men with high ROS levels compared to men with normal levels of ROS $(9,10)$.

Many medical therapies have been historically used for male fertility, including herbs, vitamins, and nutritional supplements, and many of them rely on antioxidant properties. According to EAU Guidelines on male infertility there is little scientific evidence for an empirical approach and medical therapy should be reserved only in case of hypogonadotropic hypogonadism (4). 
The aim of this manuscript is to accurately review the role of nutritional supplements in the treatment of male infertility, evaluating their effect on semen parameters and pregnancy rate.

\section{Materials AND MEthods}

The MEDLINE database was searched using PubMed with various keywords, including various combinations of search terms. "Male infertility", "nutraceuticals", "nutritional supplements", "antioxidants" and "antioxidant therapy" were the most relevant search terms, combined via Boolean operators. From the numerous search results, studies were selected on the basis of their quality: studies that were biased, incomplete or otherwise considered untrustworthy were excluded. Data were analyzed in order to provide a complete overview of the literature.

\section{RESULTS}

\section{Vitamin $E$}

Vitamin $\mathrm{E}$ is a fat-soluble vitamin belonging to the tocopherol family. It acts inhibiting free-radical-induced damage to cell membranes, preventing lipid peroxidation and improving the activity of other antioxidants. $(11,12)$. It has been demonstrated that Vitamin $\mathrm{E}$ is able to decrease seminal ROS in infertile males and there are some epidemiological data that support a direct correlation between improvement of seminal parameters and increased dietary intake of vitamin E. (13-15). Vitamin E has been widely used for the treatment of male infertility and many randomized controlled trials have been performed to assess the effect of this compound in infertile men. Pre-clinical evidences demonstrated that Vitamin E alone or in combination with Vitamin $C$ is able to reduce lipid peroxidation, improve DNA fragmentation and improve binding of the spermatozoa to the zona pellucida $(13,16,17)$. However, often these data "in vitro" do not correlate with clinical evidences. Suleiman et al. demonstrated increased sperm motility, with $21 \%$ of couples treated with $300 \mathrm{mg}$ of Vitamin E achieved pregnancy compared with $0 \%$ in the placebo group, but Kessopoulou et al. failed to demonstrate an improvement in semen parameters or seminal ROS levels compared to placebo. A recent trial assessed the synergic effect of Vitamin E, Coenzyme Q10 and Vitamin C in men with OAT. Authors demonstrated an improvement of sperm count and sperm motility after 3 and 6 months of treatment with a pregnancy rate of $28 \%$. The big limitation of this trial is the lack of a control group. (18).

\section{Vitamin C}

Vitamin $C$ is a water soluble vitamin that act as a potent antioxidant. It is involved in the synthesis of collagen, proteoglycans, and components of the intercellular matrix (19). Few studies have been published using vitamin C alone in the treatment of male infertility. So any possible effect on semen parameters could be the effect of synergistic combinations of vitamin $C$ and other antioxidants like Vitamin E, beta carotene, zinc, selenium, etc $(15,20$, 21). In vitro studies demonstrated that Vitamin $C$ plays a crucial role in preserving sperm from oxidative damage and reducing DNA fragmentation $(17,22,23)$. Dawson et coll. demonstrated the effectiveness of high dose supplementation of vitamin C (1000 mg/die), compared to placebo, in improving sperm quality (count and viability, motility and morphology) in heavy smokers (24).

\section{Vitamin A}

Vitamin A is a fat-soluble vitamin with a slight antioxidant activity (25). There is a lack of studies investigating the effect of Vitamin A alone in male fertility. Combined treatment with Vitamin A and other nutraceuticals (vitamin E, zinc, selenium, vitamin C) can improve sperm motility up to $30 \%$ in infertile man (26) and sperm count after varicocele repair (27).

\section{Arginine}

Arginine is a semi-essential amino acid which is involved in various human biochemical process as ammonia detoxification, hormone secretion and immune modulation. It is also a precursor of nitric oxide (NO) (28) and it is necessary for the synthesis of putrescine, spermidine, and spermine, which are thought to be essential to sperm motility (29). Many studies have been carried out to investigate the role of arginine supplementation in male infertility, but to date it is not possible to give evidence-based recommendation on its use. Some historical studies have reported that arginine can improve sperm concentration and motility (30-32), while others have failed to demonstrate any improvement in semen parameters or pregnancy rates $(33,34)$. There is a lack of recent, well-designed studies on arginine supplementation in male infertility, so it is difficult to conclude definitively that arginine supplementation improves male fertility.

\section{Carnitine}

Carnitines are amines derived from the synthesis of lysine and methionine. Carnitines stimulate both fatty acid breakdown and glycolysis in Sertoli cells (35) and have an antioxidant effect protecting cells from ROS. Lcarnitine and L-acetylcarnitine are concentrated in the epididymis, spermatozoa, and seminal plasma (36). Carnitines are the most studied nutritional supplements for the treatment of idiopathic male infertility. Lenzi et al. demonstrated an increase in all sperm parameters and in pregnancy rate after combined carnitine treatment (2 $\mathrm{g} / \mathrm{d}$ L-carnitine and $1 \mathrm{~g} / \mathrm{d}$ L-acetyl-carnitine for 6 months) in 60 men suffering from OAT, compared to placebo. The most significant improvement was observed in sperm motility in patients who had lower initial absolute values of motile sperm (37). Similarly, Balercia et al showed a significant improvement in both sperm motility and morphology in men treated with LCarnitine or L-Acetyl-Carnitine supplementation, for 24 weeks compared to placebo (38). The role of carnitines in patient with varicocele-associated OAT has been investigated by Cavallini et al. in a placebo controlled randomized study (39). Pregnancy rates increased in patients treated with carnitine alone or in combination with cinnoxicam, over the placebo arm. In addition, improvements in sperm concentration, motility and 
morphology were observed in patients with no varicocele or small or moderate-grade varicoceles treated with carnitine, alone or in combination with cinnoxicam, while no improvement was noted in those with large varicoceles. The combination of carnitine and nonsteroidal anti-inflammatory drugs resulted effective also in improving semen parameters in men with abacterial prostatovesiculoepididymitis and elevated seminal leukocyte concentrations (36). Other studies confirmed the positive effect of carnitine therapy on sperm count and motility (40-44). Nevertheless Sigman et al. in a randomized placebo controlled trial showed no improvements of semen parameters in men treated with carnitines (45). More recently, Busetto et al. demonstrated the beneficial effect of an antioxidant complex containing carnitines (L-carnitine, acetyl-L-carnitine, fructose, citric acid, selenium, coenzyme Q10, zinc, ascorbic acid, cyanocobalamin, folic acid) in improving sperm progressive motility compared to baseline (46).

\section{Coenzyme Q-10}

Coenzyme Q-10 (CoQ10) acts as an electron carrier in the mitochondrial respiratory chain (Hidaka et al., 2008) and therefore it is involved in mitochondrial bioenergetics, which is important in sperm maturation (47). Some studies in the past showed a positive effect of CoQ10 in improving sperm concentration and motility, although no differences in pregnancy rate were found (48-50). A more recent small trial demonstrated the effectiveness of CoQ10 in improving semen parameters in men with varicocele (51). Two big randomized placebo-controlled trials confirmed that CoQ10 and its reduced form, ubiquinol, are safe and effective in improving sperm density, sperm motility and sperm morphology in men with unexplained infertility compared to placebo arm. Patients treated with CoQ10 and ubiquinol presented higher catalase and SOD, higher inibin B levels and lower FSH if compared to placebo $(52,53)$. Safarinejad et al. found also a partner pregnancy rate of $34 \%$ in infertile men with idiopathic OAT treated with CoQ10, but this study lack of a control group (54). A recent metaanalysis concluded that there is no evidence in the literature that CoQ10 increases either live birth or pregnancy rates, but there is a global improvement in sperm parameters (55).

\section{Glutathione}

Glutathione plays a significant role in the antioxidant defences of the spermatogenic epithelium, the epididymis, and perhaps in ejaculated spermatozoa. It is produced endogenously in the liver and is one of the most abundant antioxidants found in the body (56) Few and dated studies have been published on the role of glutathione in male infertility. These data showed improved sperm motility, sperm concentration and decreased sperm DNA fragmentation in infertile men treated with glutathione or a combination of glutathione and other antioxidants (56-58). Intramuscular glutathione therapy resulted effective in increasing sperm motility in patients suffering from varicocele (57). Glutathione is not well adsorbed in gastrointestinal tract and the parenteral use represents the major limitation for this therapy.

\section{N-Acetylcysteine}

NAC is an amino acid precursor to glutathione and acts as ROS scavenger (59) (Zembron-Lacny et al., 2009). In vitro data showed a positive effect of NAC in improving total sperm motility and reducing ROS levels (60). In a randomized placebo-controlled trial, conducted in 120 men with idiopathic infertility, has been demonstrated that NAC therapy (600 mg/daily for 3 months) significantly increase seminal volume, sperm motility and viscosity (61). Another randomized trial confirmed the beneficial role of NAC alone or in combination with selenium in improving all semen parameters if compared to baseline and placebo treatment (62). Combination therapy with selenium resulted in a significant improvement of sperm count, motility and morphology, suggesting a synergistic effect.

\section{Selenium}

Selenium is an essential trace element which is involved in antioxidant reactions (63) and it seems to be necessary for normal testicular development, spermatogenesis, and the process of sperm capacitation (64). As previously described, selenium alone or in combination with other antioxidants can ameliorate sperm count, motility, and morphology (62) and many other studies confirmed the synergic activity of Selenium combined with other nutraceuticals like Vitamin E (65-67). Selenium demonstrated positive effects on male infertility, which appear synergistic when used with other supplements. Optimal dosing appears to be between 100 and $210 \mathrm{mg}$ on the basis of the studies above.

\section{Zinc}

Zinc is a trace mineral essential for normal functioning of the male reproductive system. It plays a role in testicular steroidogenesis, testicular development, spermatozoa oxygen consumption, nuclear chromatin condensation, the acrosome reaction, acrosin activity, sperm chromatin stabilization, and conversion of testosterone to 5a-dihydrotestosterone (68). Many biochemical mechanism are zinc-dependent and it acts as cofactor for more than 200 enzyme in the whole body, including those involved in DNA transcription and protein synthesis (68). Zinc deficiency is related to oligospermia, hypogonadism and compromised immune system function (69). In addition, zinc deficiency is involved in the pathogenesis of oligoasthenospermia in diabetic patients (70). A prospective randomized controlled study was carried out to investigate the effects of zinc sulfate, folic acid and combination of both on sperm quality, protamine content and acrosomal integrity after surgical treatment of varicocele. Researchers concluded that co-administration of zinc and folic acid significantly improved sperm parameters and increased varicocelectomy outcomes (71). More recently, Raigani et al. investigated in a randomised, double-blind, placebo-controlled clinical trial, the effects of folic acid and zinc sulphate supplementation on the improvement of sperm function in subfertile oligoasthenoteratozoospermic men. This study failed to demonstrate that zinc sulphate and folic acid supplementation ameliorate sperm quality in infertile men with severely compromised sperm parameters (72). 


\section{Discussion}

Despite the big amount of studies published on nutraceuticals and male infertility, to date it is not possible to give any recommendation about their use as therapy in infertile male. A significant number of studies lack randomization and placebo-controlled arms and in many cases the pregnancy rate is not the primary endpoint. Additionally, many studies have been unable to control or account for dietary intake of potential fertility-affecting food sources. In fact, usually a balanced diet cannot make it necessary the supplementation. Another limitation of the proposed studies is the inherent tendency of biological fluctuation in consecutive semen samples from the same individual, the geographical variation in semen quality, the lack of standardization in carrying out the tests used in assessing semen variables and the intra-observer and inter-observer semen assessment bias. Nevertheless, based upon the results of the selected studies, it seems that selective supplementation with nutritional supplements could have beneficial consequences on sperm parameters, even if there is a wide range of dosing regimens used across the different trials. Unfortunately, the clinical heterogeneity of the included studies meant a meta-analysis of their results could not be performed.

A systematic review published by Ross et al. in 2010, selected 17 randomized trial to evaluate the effects of oral antioxidants on sperm quality and pregnancy rate in infertile men. Their results showed that treatment of infertile men with oral antioxidants reduces seminal oxidative stress and could improve sperm motility, but has a less predictable impact on sperm concentration and morphology. Furthermore, oral antioxidant therapy was associated with a significant improvement in spontaneous and assisted conception pregnancy rates in 6 out of the 10 randomized studies included in the analysis (14).

The role of antioxidants therapy for the treatment of male infertility has been reviewed extensively by the Cochrane Collaboration (73). The primary end point of this review was to identify whether supplementation with oral antioxidants would improve outcomes of assisted reproductive techniques when used in male partners of couples undergoing assisted reproduction techniques (ART), while secondary endpoint was to assess how antioxidants may influence pregnancy rate, sperm parameters and sperm DNA fragmentation. 34 trials were included in the pooled analysis with 2876 couples in total. Antioxidants therapy is associated with a statistically significant increase in live birth rate (OR $4.85,95 \% \mathrm{CI} 1.92$ to $12.24 ; \mathrm{P}=0.0008)$ and in pregnancy rates (OR 4.18, 95\% CI 2.65 to 6.59; P < 0.00001 ), if compared with the men in control group. However, authors stated that it is not possible to draw conclusions on the effect of antioxidants on sperm parameters, due to the very poor quality of evidence in the reviewed trials and concluded that antioxidant supplementation might improve live birth and pregnancy rate outcomes for subfertile couples undergoing ART In addition, data from this review are not sufficient to draw any conclusions from the head to head comparisons between antioxidants. So, to date, one antioxidant did not appear to have any effect on pregnancy rate per couple or sperm parameters over those of another antioxi- dant (73). Starting from 2013, EAU Guidelines changed their recommendation according to these findings (4). More recently, Clark et al. reviewed 37 RCTs on complementary and alternative medicine, including antioxidant and nutritional supplements, for the treatment of male infertility. They concluded that despite some preliminary evidences of the effectiveness of CAM interventions among infertile patients, there is a need for further investigation before they can be considered for routine clinical use (74). The same conclusions have been reached by Imamovic Kumalic et al. They reviewed 32 studies from 2000 to 2013 and found that the majority of these studies confirmed beneficial effect of antioxidants on at least one of the semen parameters, with the most relevant effect on sperm motility, confirming a possible role of nutritional supplements for the treatment of idiopathic oligoasthenoteratozoospermia (75).

Comhair et al. evaluated the clinical efficacy of different treatment for male infertility by calculating the numbers needed to treat (NNT) in 4143 infertile couples, based on controlled trials. Antioxidant therapy resulted in a NNT of 7.8, while varicocele treatment yielded a NNT of 6.3. The NNT of the combination of varicocele treatment with nutraceuticals supplementation was 2.6 and combination of nutraceuticals and IVF had a NNT of 4.0. So authors concluded that there may be a trend for the use of NFS to improve the success rate of varicocele treatment and of IVF (76). Nutritional supplements are usually well tolerated and must be considered safe, nevertheless there are some possible dose-related adverse events that must be taken into consideration (Table 1).

\section{Conclusions}

Even if it is not possible to give any firm recommendation about nutritional supplementation for the treatment of idiopathic male infertility, rising evidences from randomized trials and systematic review suggests that oral antioxidant supplementation may improve semen parameters and the likelihood of pregnancy. This improvement, however, is not consistent and there is a wide variation in the treatment regimens used. There is therefore a need to plan further large randomized controlled studies, with clear inclusion/exclusion criteria, to evaluate the effect of standardized doses of specific antioxidants on both spontaneous and assisted conception pregnancy rates, in order to select the population that could benefit from oral antioxidants therapy.

\section{REFERENCES}

1. Sharlip ID, Jarow JP, Belker AM, et al. Best practice policies for male infertility Fertil Steril. 2002; 77:873-882

2. World Health Organization. WHO Manual for the Standardized Investigation and Diagnosis of the Infertile Couple. Cambridge: Cambridge University Press, 2000.

3. Cooper TG, Noonan E, von Eckardstein S, et al. World Health Organization reference values for human semen characteristics. Hum Reprod Update. 2010; 16:231-45.

4. Jungwirth A, Diemer T, Dohle GR, Giwercman A, Kopa Z, Krausz $C$, Tournaye H members of the European Association of Urology (EAU) 
Table 1. Potential adverse events of nutritional supplements.

\begin{tabular}{|c|c|c|}
\hline Vitamin E & $\begin{array}{l}\text { Gl distress } \\
\text { Fatigue } \\
\text { Muscle weakness } \\
\text { Headache } \\
\text { Blurry vision } \\
\text { Rash } \\
\text { Bruising } \\
\text { Bleeding complication (> } 800 \mathrm{IU} / \mathrm{d}) \\
\text { Cardiovascular complications }(>400 \mathrm{IU} / \mathrm{d})\end{array}$ & $\begin{array}{l}\text { Lonn et al. } 2005 \\
\text { Miller et al. } 2005 \\
\text { Alpers et al. } 2008 \\
\text { Mousa et al. } 2010\end{array}$ \\
\hline Vitamin C (> $2000 \mathrm{mg} / \mathrm{die})$ & $\begin{array}{l}\text { Dyspepsia } \\
\text { Headache } \\
\text { Increased risk of nephrolitiasis }\end{array}$ & Alpers et al. 2008 \\
\hline Vitamin A (> $50.000 \mathrm{IU} / \mathrm{d})$ & $\begin{array}{l}\text { Fatigue } \\
\text { Irritability } \\
\text { Mental status change } \\
\text { Visual disturbances } \\
\text { Vertigo } \\
\text { Anorexia } \\
\text { Gl distress } \\
\text { Excessive sweating } \\
\text { Myalgia/Arthralgia } \\
\text { Hepatotoxycity } \\
\text { Hypoplastic Anemia }\end{array}$ & Oversen et al. 1984 \\
\hline Arginine & $\begin{array}{l}\text { Gl discomfort } \\
\text { Hypotension } \\
\text { Electrolyte abnormalities } \\
\text { Renal insufficiency } \\
\text { Increased bleeding risk } \\
\text { Elevated glucose levels } \\
\text { Worsening symptoms of sickle cell disease and asthma }\end{array}$ & Appleton et al. 2002 \\
\hline Carnitine (> $4 \mathrm{~g} /$ die) & $\begin{array}{l}\text { Gl distress } \\
\text { Seizures } \\
\text { Malodorous body secretion }\end{array}$ & Rubin et al, 2001; Alpers et al, 2008 \\
\hline Coenzyme Q10 & $\begin{array}{l}\text { Gl distress } \\
\text { Loss of appetite } \\
\text { Headache } \\
\text { Skin rash }\end{array}$ & $\begin{array}{l}\text { Ko EY, Sabanegh ES Jr. } \\
\text { The role of over-the-counter supplements for the } \\
\text { treatment of male infertility-fact or fiction? } \\
\text { J Androl. } 2012 \text { May-Jun; 33(3):292-308 }\end{array}$ \\
\hline Glutathione & Not adsorbed within Gl tract & Witschi et al. 1992 \\
\hline N-Acetyl-Cisteine & $\begin{array}{l}\text { Gl distress } \\
\text { Rash } \\
\text { Fever } \\
\text { Headache } \\
\text { Drowsiness } \\
\text { Hypotension } \\
\text { Hepatic toxicity }\end{array}$ & Holdiness et al. 1991 \\
\hline Selenium (uncommon) & $\begin{array}{l}\text { Gl distress } \\
\text { Nail changes } \\
\text { Fatigue } \\
\text { Iritability } \\
\text { Hair loss } \\
\text { Garlic breath odor } \\
\text { Metallic taste } \\
\text { Muscle tenderness } \\
\text { Tremors } \\
\text { Facial flushing } \\
\text { Hematologic changes } \\
\text { Hepatic and renal insufficiency }\end{array}$ & $\begin{array}{l}\text { Yang et al. 1983; } \\
\text { Standing Committee, 2000b }\end{array}$ \\
\hline ZINC (> 200 mg/die) & $\begin{array}{l}\text { Gl distress } \\
\text { Loss of appetite } \\
\text { Dehydratation } \\
\text { Gastric ulceration } \\
\text { Rash } \\
\text { Headache }\end{array}$ & Alpers et al. 2008 \\
\hline (> $450 \mathrm{mg} / \mathrm{die})$ & $\begin{array}{l}\text { Altered iron function } \\
\text { Low copper levels } \\
\text { Sideroblastic anemia } \\
\text { Reduced immune function } \\
\text { Reduced HDL levels }\end{array}$ & Maret and Sandstead, 2006 \\
\hline
\end{tabular}


Guidelines Office. Guidelines on Male Infertility. In: EAU Guidelines, edition presented at the 28th EAU Annual Congress, Milan 2013.

5. Tremellen K. Oxidative stress and male infertility-a clinical perspective. Hum. Reprod. Update. 2008; 14:243-258.

6. Agarwal A, Sharma RK, Nallella KP, et al. Reactive oxygen species as an independent marker of male factor infertility. Fertil. Steril. 2006: 86:878-885.

7. Aitken R, Baker M. Oxidative stress and male reproductive biology. Reprod Fertil Dev. 2004; 16:581-588.

8. Agarwal A, Saleh RA, Bedaiwy MA, Role of reactive oxygen species in the pathophysiology of human reproduction. Fertil Steril. 2003; 79:829-843.

9. Smith R, Vantman D, Ponce J, et al. Total antioxidant capacity of human seminal plasma Human Reproduction 1996; 11:1655-1660.

10. Pahune PP, Choudhari AR, Muley PA. The total antioxidant power of semen and its correlation with the fertility potential of human male subjects. J Clin Diagn Res. 2013; 7:991-995.

11. Palamanda JR, Kehrer JR. Involvement of vitamin E and protein thiols in the inhibition of microsomal lipid peroxidation by glutathione. Lipids. 1993; 23:427-443.

12. Brigelius-Flohe R, Traber MG. Vitamin E: function and metabolism. FASEB J. 1999; 13:1145-1155.

13. Kessopoulou E, Powers HJ, Sharma KK, et al. A double-blind randomized placebo crossover controlled trial using the antioxidant vitamin E to treat reactive oxygen species associated male infertility. Fert Steril. 1995; 64:825-831

14. Ross C, Morriss A, Khairy $M$, et al. A systematic review of the effect of oral antioxidants on male infertility. Reprod Biomed Online. 2010; 20:711-723.

15. Eskenazi B, Kidd SA, Marks AR, et al. Antioxidant intake is associated with semen quality in healthy men. Hum Reprod (Oxf). 2005; 20:1006-1012.

16. Suleiman SA, Ali ME, Zaki ZMS, et al. Lipid peroxidation and human sperm motility: protective role of vitamin E. J Androl. 1996; 17:530-537.

17. Greco E, Iacobelli M, Rienzi L, et al. Reduction of the incidence of sperm DNA fragmentation by oral antioxidant treatment. J Androl. 2005; 26:349-353.

18. Kobori Y, Ota S, Sato R, et al. Antioxidant cosupplementation therapy with vitamin $C$, vitamin $E$, and coenzyme 210 in patients with oligoasthenozoospermia. Arch Ital Urol Androl. 2014; 86:1-4.

19. Linster CL, Van Schaftingen E. Vitamin C. Biosynthesis, recycling and degradation in mammals. FEBS J. 2007; 274:1-22.

20. Baker HW, Brindle J, Irvine DS, Aitken RJ. Protective effect of antioxidants on the impairment of sperm motility by activated polymorphonuclear leukocytes. Fert Steril. 1996; 65:411-419.

21. Omu AE, al-Azemi MK, Kehinde EO, et al. Indications of the mechanisms involved in improved sperm parameters by zinc therapy. Med Prin Pract. 2008; 17:108-116.

22. Thiele JJ, Friesleben HJ, Fuchs J, Ochsendorf FR. Ascorbic acid and urate in human seminal plasma: determination and interrelationships with chemiluminescence in washed semen. Hum Reprod (Oxf). 1995; 10:110-115.

23. Mendiola J, Torres-Cantero AM, Vioque J, et al. A low intake of antioxidant nutrients is associated with poor semen quality in patients attending fertility clinics. Fert Steril. 2010; 93:1128-1133.

24. Dawson EB, Harris WA, Teter MC, Powell LC. Effect of ascorbic acid supplementation on the sperm quality of smokers. Fertil Steril. 1992; 58:1034-1039.
25. Kamal-Eldin A, Appelqvist LA. The chemistry and antioxidant properties of tocopherols and tocotrienols. Lipids. 1996; 31:671-701.

26 Scott R, MacPherson A, Yates RW, et al. The effect of oral selenium supplementation on human sperm motility. Br J Urol. 1998; 82:76-80.

27. Galatioto GP, Gravina GL, Angelozzi G, et al.. May antioxidant therapy improve sperm parameters of men with persistent oligospermia after retrograde embolization for varicocele? World J Urol. 2008; 26:97-102

28. Appleton J. Arginine: clinical potential of a semi-essential amino. Altern Med Rev. 2002; 7:512-522.

29. Sinclair S. Male infertility: nutritional and environmental considerations. Altern Med Rev. 2000; 5:28-38.

30. Tanimura J. Studies on arginine in human semen. Part II. The effects of medication with $\mathrm{L}$-arginine- $\mathrm{HCl}$ on male infertility. Bull Osaka Med Sch. 1967; 13:84-89.

31. Schachter A, Goldman JA, Zukerman Z. Treatment of oligospermia with the amino acid arginine. J Urol. 1973; 110:311-313.

32. de Aloysio D, Mantuano R, Mauloni M, Nicoletti G. The clinical use of arginine aspartate in male infertility. Acta Eur Fertil. 1982; 13:133-167.

33. Miroueh A. Effect of arginine on oligospermia. Fertil Steril. 1970; $21: 217-219$

34. Pryor JP, Blandy JP, Evans P, et al. Controlled clinical trial of arginine for infertile men with oligozoospermia. Br J Urol. 1978; 50:47-50.

35. Palmero S, Bottazzi C, Costa M, et al. Metabolic effects of Lcarnitine on prepubertal rat Sertoli cells. Horm Metab Res. 2000; 32:87-90

36. Vicari E, LaVignera S, Calogero A. Antioxidant treatment with carnitines is effective in infertile patients with prostatovesiculoepididymitis and elevated seminal leukocyte concentrations after treatment with nonsteroidal anti-inflammatory compounds. Fertil Steril. 2002; 6:1203-1208

37. Lenzi A, Sgro P, Salacone P, et al. A placebo-controlled doubleblind randomized trial in the use of combined L-carnitine and L-acetylcarnitine treatment in men with asthenozoospermia. Fertil Steril. 2004; 81:1578-1584.

38. Balercia G, Regoli F, Armeni T, et al. Placebo-controlled doubleblind randomized trial on the use of L-carnitine, L-acetylcarnitine, or combined L-carnitine and Lacetylcarnitine in men with idiopathic asthenozoospermia. Fertil Steril. 2005; 84:662-671.

39. Cavallini G, Ferraretti AP, Gianarolli L, et al. Cinnoxicam and $L$ carnitine/acetyl-L-carnitine treatment for idiopathic and varicocoeleassociated oligoasthenospermia. J Androl. 2004; 25:761-770.

40. De Rosa M, Boggia B, Amalfi B, et al.. Correlation between seminal carnitine and functional spermatozoal characteristics in men with semen dysfunction of various origins. Drugs RD. 2005; 6:1-9.

41. Moncada ML, Vicari E, Cimino C, et al.. Effect of acetylcarnitine treatment in oligoasthenospermic patients. Acta Eur Fertil. 1992; 23:221-224.

42. Costa M, Canale D, Filicori M, et al. L-Carnitine in idiopathic asthenozoospermia: a multicenter study. Italian Study Group on Carnitine and Male Infertility. Andrologia. 1994; 26:155-159.

43. Vicari E, Calogero AE. Effects of treatment with carnitines in infertile patients with prostato-vesiculo-epididymitis. Hum Reprod (Oxf). 2001; 16:2338-2342.

44. Vitali G, Parente R, Melotti C. Carnitine supplementation in human idiopathic asthenospermia: clinical results. Drugs Exp Clin Res. 1995; 21:157-159.

45. Sigman M, Glass S, Campagnone J, Pryor JL. Carnitine for the 
treatment of idiopathic asthenospermia: a randomized, doubleblind, placebo-controlled trial. Fertil Steril. 2006; 85:1409 1414.

46. Busetto GM, Koverech A, Messano M, et al. Prospective open-label study on the efficacy and tolerability of a combination of nutritional supplements in primary infertile patients with idiopathic astenoteratozoospermia Arch Ital Urol Androl. 2012; 84:137-40.

47. Littarru GP, Tiano L. Clinical aspects of coenzyme Q10: an update. Nutrition. 2010; 26:250-254.

48. Balercia G, Buldreghini E, Vignini A, et al. Coenzyme 210 treatment in infertile men with idiopathic asthenozoospermia: a placebo-controlled, double-blind randomized trial. Fertil Steril. 2009; 91:1785-1792.

49. Balercia G, Mancini A, Paggi F, et al. Coenzyme 210 and male infertility. J Endocrinol Invest. 2009; 32:626-692.

50. Safarinejad MR. Efficacy of coenzyme Q10 on semen parameters, sperm function and reproductive hormones in infertile men. J Urol. 2009; 182:237-248.

51. Festa R, Giacchi E, Raimondo S, et al. Coenzyme 210 supplementation in infertile men with low-grade varicocele: an open, uncontrolled pilot study Andrologia. 2013 Aug 22 doi: 10.1111/and.12152.

52. Safarinejad MR, Safarinejad S, Shafiei N, Safarinejad S. Effects of the reduced form of coenzyme 210 (ubiquinol) on semen parameters in men with idiopathic infertility: a double-blind, placebo controlled, randomized study. J Urol. 2012; 188:526-31.

53. Nadjarzadeh A, Shidfar F, Amirjannati N, et al. Effect of Coenzyme Q10 supplementation on antioxidant enzymes activity and oxidative stress of seminal plasma: a double-blind randomised clinical trial.Andrologia. 2014; 46:177-83.

54. Safarinejad MR. The effect of coenzyme Q10 supplementation on partner pregnancy rate in infertile men with idiopathic oligoasthenoteratozoospermia: an open-label prospective study. Int Urol Nephrol. 2012; 44:689-700.

55. Lafuente R, González-Comadrán M, Solà I, et al. Coenzyme Q10 and male infertility: a meta-analysis. J Assist Rep. 30:1147-56.

56. Lenzi A, Lombardo F, Gandini L, et al. Glutathione therapy for male infertility. Arch Androl. 1992; 29:65-68.

57. Lenzi A, Culasso F, Gandini L, et al. Placebo-controlled, double blind, cross-over trial of glutathione therapy in male infertility. Hum Reprod (Oxf). 1993; 8:1657-1662.

58. Lenzi A, Picardo M, Gandini L, et al. Glutathione treatment of dyspermia: effect on the lipoperoxidation process. Hum Reprod (Oxf). 1994; 9:2044-2050.

59. Zembron-Lacny A, Slowinska-Lisowska M, Szygula Z, et al. The comparison of antioxidant and hematological properties of $\mathrm{N}$-acetylcysteine and alpha-lipoic acid in physically active males. Physiol Res. 2009; 58:855-861.

60. Oeda T, Henkel R, Ohmori H, Schill WB. Scavenging effect of Nacetyl- L-cysteine against reactive oxygen species in human semen: a possible therapeutic modality for male factor infertility? Andrologia. 1997; 29:125-131.

61. Ciftci H, Verit A, Savas M, et al. Effects of N-acetylcysteine on semen parameters and oxidativelantioxidant status. Urology. 2009; 74:73-76.

62. Safarinejad MR, Safarinejad S. Efficacy of selenium and/or Nacetylcysteine for improving semen parameters in infertile men: a doubleblind, placebo controlled, randomized study. J Urol. 2009; 181:741-751.

63. Brown KM, Arthur JR. Selenium, selenoproteins and human health: a review. Public Health Nutr. 2001; 4:593-599.
64. Ursini F, Heim S, Kiess M, et al. Dual function of the selenoprotein PHGPx during sperm maturation. Science. 1999; 285:1393-1396.

65. Burton GW, Traber MG. Vitamin E: antioxidant activity, biokinetics, and bioavailability. Annu Rev Nutr. 1990; 10:357-382.

66. Vezina D, Mauffette F, Roberts KD, Bleau G. Selenium-vitamin E supplementation in infertile men. Effects on semen parameters and micronutrient levels and distribution. Biol Trace Elem Res.1996; 53:65-83

67. Keskes-Ammar L, Feki-Chakroun N, Rebai T, et al. Sperm oxidative stress and the effect of an oral vitamin $\mathrm{E}$ and selenium supplement on semen quality in infertile men. Arch Androl. 2003; 49:83-94.

68. Ebisch IM, Thomas CM, Peters WH, et al. The importance of folate, zinc and antioxidants in the pathogenesis and prevention of subfertility. Hum Reprod (Oxf). 2007; 13:163-174.

69. Prasad AS. Zinc in human health: effect of zinc on immune cells. Mol Med. 2008; 14:353-357.

70. Zhao Y1, Zhao H, Zhai X, et al. Effects of Zn deficiency, antioxidants, and low-dose radiation on diabetic oxidative damage and cell death in the testis. Toxicol Mech Methods. 2013; 23:42-7.

71. Azizollahi G, Azizollahi S, Babaei H, et al. Effects of supplement therapy on sperm parameters, protamine content and acrosomal integrity of varicocelectomized subjects. J Assist Reprod Genet. 2013; 30:593-9.

72. Raigani M, Yaghmaei B, Amirjannti N, et al. The micronutrient supplements, zinc sulphate and folic acid, did not ameliorate sperm functional parameters in oligoasthenoteratozoospermic men. Andrologia. 2013 Oct 23.

73. Showell MG, Brown J, Yazdani A, et al. Antioxidants for male subfertility. Cochrane Database Syst Rev. 2011; 1:CD007411.

74. Clark NA, Will M, Moravek MB, Fisseha S. A systematic review of the evidence for complementary and alternative medicine in infertility. Int J Gynaecol Obstet. 2013; 122:202-6.

75. Imamovic Kumalic S, Pinter B. Review of Clinical Trials on Oligoasthenoteratozoospermia. Biomed Res Int. 2014; 2014:426951.

76. Comhaire F, Decleer W. Comparing the effectiveness of infertility treatments by numbers needed to treat (NNT). Andrologia. 2012; 44:401-4.

\section{Correspondence}

Davide Arcaniolo, MD

Massimiliano Creta, MD - max.creta@gmail.com

Department of Urology, University of Federico II, Naples, Italy

Vincenzo Favilla, MD

Department of Urology, University of Catania, Catania, Italy

Daniele Tiscione, $M D$

Tommaso Cai, MD - ktommy@libero.it

Department of Urology, Santa Chiara Hospital, Trento, Italy

Francesca Pisano, MD

Department of Urology, University of Turin, Turin, Italy

Giorgio Bozzini, MD

Department of Urology, Istituto di Ricovero e Cura a Carattere Scientifico, Policlinico San Donato, University of Milan, Milan, Italy

Massimiliano Creta, MD

Department of Urology, University of Federico II, Naples, Italy

Giorgio Gentile, MD

Department of Urology, Azienda Ospedaliero-Universitaria Policlinico S.Orsola-Malpighi, Bologna, Italy

Filippo Menchini Fabris, MD

Department of Urology, University of Pisa, Pisa, Italy

Nicola Pavan, MD

Department of Urology, University of Trieste, Trieste, Italy

Italo Antonio Veneziano, MD

Department of Urology, Ospedale Madonna delle Grazie, Matera, Italy 